\title{
STARZ Spartacus
}




\section{Screening Antiquity}

\section{Series Editors: Monica S. Cyrino and Lloyd Llewellyn-Jones}

Screening Antiquity is a cutting-edge and provocative series of academic monographs and edited volumes focusing on new research on the reception of the ancient world in film and television. Screening Antiquity showcases the work of the best-established and up-and-coming specialists in the field. It provides an important synergy of the latest international scholarly ideas about the conception of antiquity in popular culture and is the only series that focuses exclusively on screened representations of the ancient world.

\section{Editorial Advisory Board}

Antony Augoustakis, University of Illinois, Urbana-Champaign, USA

Alastair Blanshard, University of Queensland, Australia

Robert Burgoyne, University of St Andrews, UK

Lisa Maurice, Bar-Ilan University, Israel

Gideon Nisbet, University of Birmingham, UK

Joanna Paul, Open University, UK

Jon Solomon, University of Illinois, Urbana-Champaign, USA

Titles available in the series:

Rome Season Two: Trial and Triumph

Edited by Monica S. Cyrino

Ben-Hur: The Original Blockbuster

By Jon Solomon

Cowboy Classics: The Roots of the American Western in the Epic Tradition By Kirsten Day

STARZ Spartacus: Reimagining an Icon on Screen

Edited by Antony Augoustakis and Monica S. Cyrino

Forthcoming Titles:

Broadcasting Ancient Greece on Television

Edited by Fiona Hobden and Amanda Wrigley 


\section{STARZ Spartacus \\ Reimagining an Icon on Screen}

Edited by Antony Augoustakis and

Monica S. Cyrino 
Edinburgh University Press is one of the leading university presses in the UK. We publish academic books and journals in our selected subject areas across the humanities and social sciences, combining cutting-edge scholarship with high editorial and production values to produce academic works of lasting importance. For more information visit our website: edinburghuniversitypress.com

(C) editorial matter and organisation Antony Augoustakis and Monica S. Cyrino, 2017

(C) the chapters their several authors, 2017

Edinburgh University Press Ltd

The Tun - Holyrood Road, I2(2f) Jackson's Entry, Edinburgh EH8 8PJ

Typeset in $\mathrm{I} / \mathrm{I} 33$ Sabon by Servis Filmsetting Ltd, Stockport, Cheshire and printed and bound in Great Britain by CPI Group (UK) Ltd, Croydon CRo 4YY

A CIP record for this book is available from the British Library

ISBN 978 I 474407847 (hardback)

ISBN 978 I 474407854 (webready PDF)

ISBN 978 I 47440786 I (epub)

The right of Antony Augoustakis and Monica S. Cyrino to be identified as the editors of this work has been asserted in accordance with the Copyright, Designs and Patents Act I988, and the Copyright and Related Rights Regulations 2003 (SI No. 2498). 